\title{
Hydraulic performance of fish guidance structures with curved bars - Part 2: flow fields
}

\section{Journal Article}

Author(s):

Beck, Claudia (D); Albayrak, Ismail (D); Meister, Julian (D); Boes, Robert (iD)

Publication date:

2020

Permanent link:

https://doi.org/10.3929/ethz-b-000387342

Rights / license:

Creative Commons Attribution-NonCommercial 4.0 International

Originally published in:

Journal of Hydraulic Research 58(5), https://doi.org/10.1080/00221686.2019.1671516

Funding acknowledgement:

727830 - Fishfriendly Innovative Technologies for Hydropower (SBFI) 


\section{Hydraulic performance of fish guidance structures with curved bars -}

Part 2: Flow fields

Claudia Beck, Ismail Albayrak, Julian Meister, Robert M. Boes

"This is an Accepted Manuscript of an article published by Taylor \& Francis in Journal of Hydraulic Research on 17.12.2019, available online:

https://www.tandfonline.com/doi/full/10.1080/00221686.2019.1671516

To cite this version:

Beck, C., Albayrak, I., Meister, J., Boes R.M. (2020). Hydraulic performance of fish guidance structures with curved bars - Part 2: Flow fields. Journal of Hydraulic Research, 58(5): 819-830, https://doi.org/10.1080/00221686.2019.1671516.

"This is an Accepted Manuscript version of the following article, accepted for publication in Journal of Hydraulic Research. Beck, C., Albayrak, I., Meister, J., Boes R.M. (2020). Hydraulic performance of fish guidance structures with curved bars-Part 2: Flow fields. Journal of Hydraulic Research, 58(5): 819-830, https://doi.org/10.1080/00221686.2019.1671516. It is deposited under the terms of the Creative Commons Attribution-NonCommercial License (http://creativecommons.org/licenses/by-nc/4.0/), which permits non-commercial re-use, distribution, and reproduction in any medium, provided the original work is properly cited." 
Hydraulic performance of fish guidance structures with curved bars - Part

\section{2: Flow fields}

CLAUDIA BECK, MSc. Environmental Engineer, PhD Student, Laboratory of Hydraulics, Hydrology and Glaciology (VAW), ETH Zurich, Zürich, Switzerland

Email: beck@vaw.baug.ethz.ch (author for correspondence)

ISMAIL ALBAYRAK (IAHR Member), Dr., Research Scientist, Laboratory of Hydraulics, Hydrology and Glaciology (VAW), ETH Zurich, Zürich, Switzerland

Email: albayrak@vaw.baug.ethz.ch

JULIAN MEISTER, MSc. Environmental Engineer, PhD Student, Laboratory of Hydraulics, Hydrology and Glaciology (VAW), ETH Zurich, Zürich, Switzerland

Email: meister@vaw.baug.ethz.ch

ROBERT M. BOES (IAHR Member), Prof. Dr., Director, Laboratory of Hydraulics, Hydrology and Glaciology (VAW), ETH Zurich, Zürich, Switzerland

Email: boes@vaw.baug.ethz.ch

Running Head: Flow fields at curved-bar racks for fish guidance 


\title{
Hydraulic performance of fish guidance structures with curved bars - Part
}

\section{2: Flow fields}

\begin{abstract}
The current geometric designs of fish guidance structures with vertical bars for run-of-river hydropower plants result in high head losses and asymmetric turbine admission flow. To address these issues, we develop innovative curved bar designs and experimentally investigate different rack configurations with curved bars in a laboratory flume. The present paper (part II) focuses on the hydraulic performance of the novel curved bar designs with regard to flow fields, while the companion paper (part I) reports the results on the head losses. The detailed flow fields obtained by 3D velocity measurements show that the curved bars promote flow conditions favourable for both fish guidance and turbine operation. The flow straightening effect of the curved bars leads to quasi-symmetrical turbine admission flow and reduced head losses. The findings are discussed with regard to fish protection and guidance, and optimal engineering application.
\end{abstract}

Keywords: curved-bar rack; fish downstream migration; fish guidance; flow field, hydraulic perfomance

\section{Introduction}

Fish Guidance Structures (FGSs) with vertical bars are effective mechanical and behavioural barriers to protect and guide downstream migrating fish at water intakes (Bates \& Vinsonhaler, 1957; Electric Power Research Institute [EPRI] \& Dominion Millstone Laboratories [DML], 2001; Amaral, Winchell, McMahon, \& Dixon, 2003; Boes \& Albayrak, 2017). However, the current geometric design of these FGSs cause high head losses and unfavourable up- and downstream flow fields, which are critical factors for the successful implementation of FGSs at run-of-river HydroPower Plants (HPPs) (Raynal, Chatellier, Courret, Larinier, \& David, 2013; Moretti, 2015; Albayrak, Kriewitz, Hager, \& Boes, 2017). To address these issues, we develop innovative curved bar shapes for FGSs and investigate their hydraulic performances in a laboratory flume. Part I of this study reports the results on the head losses (Beck, Albayrak, Meister, \& Boes, 2019) while the present paper (part II) focuses on the flow fields around the FGSs with the novel curved bars. In the following, a brief literature review on FGSs, their hydraulic performance and Fish Guidance Efficiency (FGE) are presented and the research gaps are highlighted.

Fish guidance structures are bar racks installed in front of a water intake at an angle to the flow direction in plan view, $\alpha=15^{\circ} \div 30^{\circ}$. Depending on the bar angle to the flow direction $\beta$ in plan view (also called flow attack angle), FGSs are classified as louvres with $\beta=90^{\circ}$, angled bar racks with $\beta=90^{\circ}-\alpha$, and Modified angled Bar Racks (MBRs) with $\beta \neq 90^{\circ}-\alpha$ (cf. Fig. 1 in 
Beck et al., 2019; Amaral, 2003; EPRI \& DML, 2001; Raynal et al., 2013; Albayrak et al., 2017). The clear bar spacing typically ranges between $s=25 \div 100 \mathrm{~mm}$. These FGSs induce hydraulic cues such as turbulent shear zones around the bars, deflecting the flow along the rack leading to a higher velocity component parallel to the rack $v_{p}$ compared to the velocity component normal to the rack $v_{n}$ (EPRI \& DML, 2001; Kriewitz 2015). When approaching a FGS, fish perceive these hydraulic cues, react with avoidance and follow $v_{p}$ toward a bypass system at the rack foot (Amaral, 2003). The bar and rack angles, bar shape, clear bar spacing and bypass design are essential parameters strongly influencing the hydraulic performance, i.e. upand downstream flow fields and fish guidance efficiency of the FGSs.

The flow field upstream of various FGSs was investigated by means of laboratory experiments (Katopodis, Ead, Standen, \& Rajaratnam, 2005; Shepherd, Katopodis, \& Rajaratnam, 2007; Chatellier, Wang, David, Courret, \& Larinier, 2011; Raynal et al., 2013; Albayrak, Kriewitz, Beck, $\&$ Boes, 2015). These studies report that the flow velocity increases toward the bypass, reaching up to $U_{\max }=(1.6 \div 2.5) U_{o}$ for louvres and $(1.2 \div 1.6) U_{o}$ for MBRs, depending on the rack angle and the bypass operation, with $U_{\max }=$ maximum mean flow velocity and $U_{o}=$ mean approach flow velocity (Bates \& Vinsonhaler, 1957; Ducharme, 1972; EPRI \& DML, 2001; Shepherd et al., 2007 and Albayrak et al., 2015). The results from field and laboratory tests with live-fish revealed that the FGE through a bypass could be impaired by unfavourable hydraulic conditions at the bypass entrance, i.e. locally decreased flow velocities, even if fish guidance along the rack was high. The ratio of approach flow velocity to bypass entrance velocity of $1.1 \div$ 1.5 is recommended for louvres (United States Bureau of Reclamation USBR, 2006) and is expected to be similar for other FGSs. Albayrak et al. (2015) further report a strong flow deflection for louvres leading to a non-uniform flow distribution along the rack and a negative transverse component through the rack of up to $-0.5 U_{o}$ directly in front of the bypass entrance. Despite similar flow patterns, Albayrak et al. (2015) also report that flow deflection and acceleration reduced and flow diversion through the rack was more uniform along the rack for MBRs compared to louvres. To allow fish to actively remain in front of the rack and hence avoid fish entrainment through the rack, Bates \& Vinsonhaler (1957) suggest that $v_{n}$ should be smaller than the sustained swimming speed of fish, which is around $0.5 \mathrm{~m} \mathrm{~s}^{-1}$ for many fish but can be lower for small fish or eels (Ebel, 2016). Courret \& Larinier (2008) further proposed the criterion of $v_{p} / v_{n}>1$ along the rack to effectively guide fish along the rack toward the bypass. Various studies link the observed fish behaviour to hydrodynamic cues such as spatial velocity gradients or turbulence flow characteristics (Enders, Gessel, Anderson, \& Williams, 2012; Silva, Katopodis, Tachie, Santos, \& Ferreira, 2016). Haro, Odeh, Noreika, \& Castros-Santos (1998) and Nestler, Goodwin, Smith, Anderson, \& Li (2008) observed that fish avoided sudden velocity changes and used mild velocity gradients to optimize their energy expenditure during migration. 
Studies report significantly increased FGE when bypass design and operation are adapted to meet the above mentioned criteria (Nestler et al., 2008; USBR, 2011). Furthermore, live-fish experiments revealed higher FGEs for louvres of small angle $\alpha=15^{\circ}$, leading to milder velocity gradients compared to louvres with larger angles $\left(\alpha=45^{\circ}\right)$ (EPRI \& DML, 2001; Amaral et al., 2003). A recent study demonstrates that the FGEs are significantly higher for MBRs than for louvres for European fish species (Boes, Albayrak, Kriewitz, \& Peter, 2016).

Energy losses originate not only from the rack head losses but also from decreased turbine efficiency associated with the rack effect on the downstream flow. The flow field properties at the turbine intake significantly affect the turbine efficiency. According to Godde (1994), the following criteria for the turbine admission flow should be met for a symmetrical flow distribution and hence high turbine efficiency: (i) The mean flow velocity in each intake quadrant should not deviate by more than $10 \%$ from the mean admission flow velocity, (ii) the mean flow discharge in each vertical intake half should amount to between $47.5 \%$ and $52.5 \%$ of the total admission flow discharge. Raynal et al. (2013) reported a highly asymmetric flow field downstream of an angled bar rack with $\alpha=45^{\circ}$, with a large recirculation zone on the flume side downstream of the rack foot leading to accelerated flow on the opposite flume side. Kriewitz (2015) and Moretti (2015) reported similar flow patterns for louvres and MBRs. Bates and Vinsonhaler (1957) suggested flow straightening vanes to reorganize the flow downstream of a louvre, eliminate the backwater effect, and achieve an evenly distributed flow diversion toward the turbines. Shepherd et al. (2007) introduced curved bars and showed that these improved the upstream flow field with $U_{\max }=1.7 U_{o}$ compared to the rectangular bars with $U_{\max }$ $=2.5 U_{o}$. Although the authors did not quantify the downstream flow fields, these results indicate that curved bars can be an alternative to vanes not only for louvres but also for MBRs. In the present study, we therefore developed and tested racks with innovative curved bar shapes (termed 'Curved-Bar Racks' (CBRs) hereafter) to further improve the hydraulic performance of such FGSs. This paper reports the results from the systematic laboratory investigation of CBRs with a focus on (i) effects of basic rack and bar shape parameters on the flow field; (ii) effects of top, top \& bottom, and bottom overlays; and (iii) the implications of the findings for an optimum engineering design of FGSs. Optimizing the design of FGSs will not only lead to a higher FGE but also mitigate negative economic impacts on hydropower production from head losses and asymmetric turbine admission flow.

\section{Experimentation}

Velocity measurements were conducted at a 1:2 Froude-scaled detail model in an open channel flume. A detailed description of the flume setup is given in the accompanied paper of Part I (Beck et al., 2019). 


\subsection{Parameter range and test programme}

A top view of the experimental set-up and the velocity measurement grid is shown in Fig. 1a. The flume coordinates in the streamwise, spanwise and vertical directions are defined as $x, y$ and $z$, respectively (Fig. 1a), while the rack coordinates in the rack normal, parallel and vertical directions are $x^{\prime}, y^{\prime}$ and $z$, respectively (grey line in Fig. 1a). Two types of curved bars differing from each other with an angle of attack $\beta=45^{\circ}$ and $90^{\circ}$ were used. Both bar types have an outflow angle of $\delta=0^{\circ}$ parallel to the downstream channel walls (Fig. 1b). The bars are rounded at both ends with $r=t / 2$ and have a thickness $t=10 \mathrm{~mm}$ and a bar depth $d=100 \mathrm{~mm}$ at prototype scale. The investigated CBRs were horizontally angled to the flow with $\alpha=15^{\circ}, 30^{\circ}$ and $45^{\circ}$ with corresponding rack lengths of $l_{\mathrm{R}}=1.93 \mathrm{~m}, 1.0 \mathrm{~m}$ and $0.71 \mathrm{~m}$, respectively. Additionally, the effects of top and/or bottom overlays with overlay height $h_{T o}$ and $h_{B o}$, on the flow field were investigated. The relevant hydraulic parameters are the flume width $w_{c h}$, the approach flow depth $h_{o}$ and the approach flow velocity $U_{o}=Q /\left(h_{o} \cdot w_{c h}\right)$.

The test matrix included CBR configurations with $\alpha=15^{\circ}, 30^{\circ}$ and $45^{\circ}, \beta=45^{\circ}$ and $90^{\circ}$ and clear bar spacing $s=0.025 \mathrm{~m}(s=0.05 \mathrm{~m}$ in prototype, Table 1$)$. The dimensionless bar spacing is defined as $\sigma=t /(t+s)=0.17$. The effect of overlays was investigated for one CBR configuration with $\alpha=30^{\circ}, \beta=45^{\circ}$ and $s=0.05 \mathrm{~m}$. Relative overlay heights of $h_{T o} / h_{o}$ or $h_{B o} / h_{o}=$ $10,15,25 \%$ were tested for top and bottom overlays separately. For the combination of top and bottom overlays, $h_{v} / h_{o}=20$ and $30 \%$ were considered corresponding to $10 \%$ and $15 \%$ for each top and bottom overlay, respectively, with $h_{v}=h_{T o}+h_{B o}$. Identical to the companion paper (Part I), all CBR configurations were tested at a steady approach flow depth $h_{o}=0.4 \mathrm{~m}$ for a discharge of $Q=1001 \mathrm{~s}^{-1}$ resulting in an averaged approach flow velocity $U_{o}=0.5 \mathrm{~m} \mathrm{~s}^{-1}$, a bar Reynolds number $\mathrm{R}_{b}=t \cdot U_{o} / v=2,500$ with $v=1.01 \cdot 10^{-6}$ for water of $20^{\circ} \mathrm{C}$, approach flow Reynolds number $\mathrm{R}=4 \cdot R_{h} \cdot U_{o} / v=3.1 \cdot 10^{5}$ based on the hydraulic radius $R_{h}=h \cdot w_{c h} /\left(2 h+w_{c h}\right)$, and the approach flow Froude number $\mathrm{F}=U_{o} /\left(g \cdot h_{o}\right)^{0.5}=0.25$ (all previous numbers in model dimensions).

\subsection{Experimental procedure}

The streamwise $u$, spanwise $v$, and vertical $w$ instantaneous velocities were measured with a down-looking Acoustic Doppler Velocimetry probe (ADV; Sontek) at $25 \mathrm{~Hz}$ for a sampling period of 30-120 s. Post-processing was carried out with WinADV, data points with less than $70 \%$ correlation were excluded and all data were de-spiked with the Goring \& Nikora filter (Lane, S. M., Biron, K. F., Bradbrook, K. F., Butler, J. B., Chandler, J. H., Crowell, M. D., McLelland, S. J., Richards, K. S., \& Roy, A.G., 1998; Goring, D. G. \& Nikora V. I., 2002). The time-averaged velocity components in streamwise, spanwise and vertical directions are denoted by $U, V$ and $W$, respectively, so that the resulting velocity $U_{r}=\left(U^{2}+V^{2}+W^{2}\right)^{0.5}$. 
Due to geometrical restrictions of the ADV probe, measurements were taken at least $0.05 \mathrm{~m}$ away from each flume wall and $0.06 \mathrm{~m}$ below the water surface. For the six basic CBR configurations without overlays (Tests A1-A6), flow velocities were measured in three horizontal planes at $z / h_{o}=0.25,0.50,0.75$ (Table 1). The streamwise distance between measuring points was $0.1 \mathrm{~m}$ in the vicinity of the rack and $0.5 \mathrm{~m}$ further up- and downstream, while the spanwise distances were $0.1 \mathrm{~m}$ and $0.2 \mathrm{~m}$, respectively. Additional measurements were taken along the rack at a perpendicular distance of $50 \mathrm{~mm}$ upstream of the rack. The velocity components in $x^{\prime}, y^{\prime}$ and $z$ directions, i.e. the rack coordinate system (grey line in Fig. 1a), are denoted by $v_{n}, v_{p}$ and $v_{z}$, respectively. To assess the turbine admission flow distribution, flow velocities were measured at several cross sections downstream of the rack.

Various blockage ratios of top, top \& bottom, and bottom overlays were investigated only for test A3. This configuration was selected since its rack head loss coefficient $\xi_{R}$ is the lowest amongst others (cf. Table 1 and Beck et al., 2019) and its FGE is expected to be similar to the high FGE of the corresponding MBR configuration tested with various fish species (Boes \& Albayrak, 2017). To assess the effect of overlays on the flow field, velocity measurements were conducted in the horizontal plane close to the bottom at $z / h_{o}=0.075$ for the bottom overlay and close to the water surface at $z / h_{o}=0.85$ for the top overlay (Tests B1-B6, Table 1).

\section{Results}

\subsection{Up- and downstream flow fields}

Figure 2 shows the time-averaged longitudinal and transversal flow velocities $U$ and $V$ normalized by $U_{o}$ for the tests $\mathrm{A} 3$ and A4 measured at $z / h_{o}=0.5$. The rack starts affecting the flow distribution from approx. $x / h_{o}=-3.25$. Starting at the rack head $\left(x / h_{o}=-2.5\right)$ velocities gradually increase to the maximum value $U_{\max }=1.27 U_{o}$ and $U_{\max }=1.87 U_{o}$ toward the rack foot for $\beta=45^{\circ}$ (A3) and $\beta=90^{\circ}$ (A4), respectively (Fig. 2a and c, Table 2). The projected area of the bars in the flow cross section decreases with decreasing $\beta$ values, resulting in a mild flow deflection and a more gradual velocity increase for A3 compared to A4.

The maximum spatial velocity gradient toward the rack foot is $\left(\Delta U_{r} / \Delta x\right)_{\max }=0.7 \mathrm{~s}^{-1}$ for A4, which is significantly higher than for A3 with $\left(\Delta U_{r} / \Delta x\right)_{\max }=0.4 \mathrm{~s}^{-1}$. Positive transverse velocities $V$ along the upstream side of the rack are observed for both A3 and A4 (Fig. 2b and d). Although $V$ decreases toward the rack foot, it remains positive.

For A4 with $\beta=90^{\circ}$ the more pronounced upstream flow deflection leads to negative transverse flow velocities of up to $-0.8 U_{o}$ and highly asymmetric flow distribution with a return flow zone downstream of the rack, which extends up to the end of the experimental flume $\left(x / h_{o}=5.5\right)$ (Fig. $2 \mathrm{c}$ ). Compared to $\mathrm{A} 4$, the more mildly curved bars of $\mathrm{A} 3$ with $\beta=45^{\circ}$ cause a strong flow 
straightening effect resulting in a quasi-symmetrical velocity distribution downstream of the rack with only a slight velocity decrease close to the left channel wall (Fig. 2a). The up- and downstream flow fields described for A3 and A4 are similar for A1, A5 with $\beta=45^{\circ}$ and A2, A6 with $\beta=90^{\circ}$, respectively (Table 2 ).

\subsection{Flow field along the rack}

Figure 3 shows the velocity components $v_{n}, v_{p}$ and $v_{z}$ normalized with $U_{o}$ measured along the rack for the tests A1-A6. Since the trends are similar at different measuring planes, only the results at $z / h_{o}=0.5$ are shown in Fig. 3. The $v_{n} / U_{o}$ and $v_{p} / U_{o}$ values increase along the rack for all CBRs with the highest values at the rack foot $\left(y^{\prime} / l_{R}=0.9\right)$ with $v_{p}$ being the dominant component. The streamwise velocity increase toward the rack foot is less pronounced for lower $\alpha$ values leading to lower $v_{n} / U_{o}$ values (Fig. 3a). The increase rate of $v_{n} / U_{o}$ along the rack also becomes significantly lower with decreasing $\alpha$ and $\beta$ values (Fig. 3a) indicating less flow deflection and a more uniform flow distribution along the rack for low $\alpha$ and $\beta$ values. The dashed line in Fig. 3a marks the criterion $v_{n}<0.5 \mathrm{~m} \mathrm{~s}^{-1}$ for $U_{o}=0.5 \mathrm{~m} \mathrm{~s}^{-1}$, hence the threshold is only exceeded at the rack foot for A2. Note that for higher $U_{o}$ values, the threshold line is shifted to the left. The parallel velocity components $v_{p} / U_{o}$ generally increase with decreasing $\alpha$ values. The highest $v_{p} / U_{o}$ values occur for A4 (Fig. 3b). The vertical velocity components $v_{z} / U_{o}$ are almost zero along the rack. Slightly negative $v_{z} / U_{o}$ values are measured at the rack foot.

The $v_{p} / v_{n}$ ratios are above 1 for all CBR configurations meeting the criterion $v_{p} / v_{n}>1$ proposed by Courret $\&$ Larinier (2008) (Fig. 3c). The $v_{p} / v_{n}$ ratios decrease along the rack indicating the strongest flow deflection toward the opposite channel wall at the rack head and more flow being diverted to the downstream channel at the rack foot. Lower $\alpha$ values lead to higher $v_{p} / v_{n}$ ratios due to the geometrical decomposition of $v_{p}$ and $v_{n}$ on the one hand. On the other hand, stronger flow deflection for higher $\alpha$ and $\beta$ values leads to higher $v_{n}$ values at the rack foot and hence lower $v_{p} / v_{n}$ ratios.

\subsection{Hydraulics of CBRs with overlays}

Different blockage ratios of top, top \& bottom, and bottom overlays were investigated for CBR test configuration A3 (B1 - B6). Figure 4 shows the time-averaged longitudinal and transversal flow velocities $U$ and $V$ normalized by $U_{o}$ for A3 without overlay and B6 (15\% bottom overlay) measured close to the flume bottom at $z / h_{o}=0.075$. The bottom overlay completely deflects the flow toward the rack foot leading to significantly higher $V$ values along the entire rack (Fig. 4d) compared to the no-overlay configuration A3 (Fig. 4b). At this plane, no flow diversion through the CBR occurs for B6 and hence the risk of fish entrainment near the bed is minimized. The downstream flow field is symmetrical from $x / h_{o}=0$ for A3 and from $x / h_{o}=2$ for B6. 
Figure 5 shows the contour plot of $v_{p} / v_{n}$ ratios along the rack with the resulting velocity vectors of parallel and vertical velocities $v_{p, z} / U_{o}$ for A3, B4, B5 and B6. For A3, a gradual decrease of $v_{p} / v_{n}$ is observed. With a top overlay (B4), $v_{p} / v_{n}$ values are high in front of the overlay with a uniform distribution along the rack (Fig. 5b). Minimum $v_{p} / v_{n}$ values for B4 are lower compared to A3 and are shifted from the rack foot toward the rack centre. Analogous effects are observed for a bottom overlay (B6). With a top and a bottom overlay combined (B5), $v_{p} / v_{n}$ values are highest in front of both overlays.

The resulting velocity vectors $v_{p, z} / U_{o}$ are parallel for A3 indicating low $v_{z}$ values. The $v_{p, z} / U_{o}$ vectors in front of top or bottom overlays show that flow is diverted downwards or upwards, respectively, leading to higher velocities between the overlays, hence locally reducing $v_{p} / v_{n}$ values. Despite this fact, the $v_{p} / v_{n}$ values are higher than 1 for all rack configurations.

\subsection{Downstream flow field and turbine admission flow}

Figure 6 shows the effect of $\beta$ and top $\&$ bottom overlay on the admission flow distribution with contour plots of the resulting velocity $U_{r}$ normalized with $U_{o}$ for the tests A3 and A4 at $x / h_{o}=$ 3.5. The flow cross section, which is defined by the downstream flow depth and width, is divided in four equal quadrants to evaluate the deviation of the flow velocity in each quadrant from the mean flow velocity in the cross section according to Godde (1994). The downstream flow field for A4 $\left(\beta=90^{\circ}\right)$ is highly asymmetric with high flow concentration along the right downstream channel wall. None of the two turbine admission flow criteria are fulfilled (Fig. 6a). For A3 $\left(\beta=45^{\circ}\right)$, quasi-symmetrical admission flow is seen and both velocity and discharge criteria are fulfilled (Fig. 6b). The flow straightening effect of the curved bars is stronger for lower $\beta$ values causing a smaller recirculation zone downstream of the rack. Note the difference between the downstream water levels of A3 and A4 indicating significantly higher head losses for A4 compared to A3 (cf. Table 2).

The values of velocities per intake quadrant and discharges per intake half are listed for all rack configurations in Table 2. The column to the right of the admission flow distribution criterion indicates whether the criterion is fully (+), nearly (o) or not (-) met. For $\beta=45^{\circ}$ (A1, A3, A5) both criteria are fully met. For $\beta=90^{\circ}$, values slightly deviate from the criteria for $\alpha=15^{\circ}$ (A6), whereas the criteria are not met for $\alpha=30^{\circ}, 45^{\circ}$ (A2, A4). Although the application of a bottom overlay leads to lower flow velocities near the water surface (first and second quadrant), both admission flow criteria for B3 and B6 are fulfilled. Conversely, the application of a top overlay leads to lower flow velocities near the bottom (third and fourth quadrant) and only the discharge criterion is fulfilled for B1 and B4. If both top and bottom overlays are applied (B2, B5), the flow concentrates on the right side of the downstream channel, i.e. the admission flow quality deteriorates further and the criteria are no longer fulfilled for B5 (Fig. 6c). 


\section{Discussion}

\subsection{Comparison with literature data}

Kriewitz (2015) conducted PIV measurements assessing the flow field of louvres and MBRs. The comparison to the flow fields of CBRs shown in the present study reveals that the curved bar shape leads to a significant reduction of $U_{\max }$ compared to the equivalent rack configurations with straight bars from $1.75 U_{o}$ for the MBR to $1.25 U_{o}$ for the equivalent CBR A1 $\left(\alpha=45^{\circ}, \beta=\right.$ $\left.45^{\circ}\right)$, from $2.25 U_{o}$ to $1.66 U_{o}$ for A2 $\left(\alpha=45^{\circ}, \beta=90^{\circ}\right)$, and from $1.70 U_{o}$ to $1.27 U_{o}$ for $\mathrm{A} 3(\alpha=$ $30^{\circ}, \beta=45^{\circ}$ ) (Table 2). These results demonstrate that the curved bars reduce the flow deflection leading to a more uniform flow distribution along the rack, hence reducing $U_{\max }$ compared to straight bars.

Velocity components along the rack were studied for angled bar racks with $s=10 \div 30 \mathrm{~mm}$ clear bar spacing by Raynal et al. (2013). For $\alpha=45^{\circ}$, angled bar racks are comparable to CBRs since $\beta$ is $45^{\circ}$ for both FGS-types. The $v_{p} / U_{o}$ distributions are similar for angled bar racks with $s$ $=15 \mathrm{~mm}$ and CBRs with $s=50 \mathrm{~mm}$ in the present study (upscaled to 1:1). The $v_{n}$ values are similar at the rack head but increase more sharply for angled bar racks up to $1.2 U_{o}$ as compared to CBRs up to $0.8 U_{o}$. This comparison indicates that the narrow bar spacing of $s=15 \mathrm{~mm}$ increases the flow contraction toward the rack foot hence increasing the normal velocities. Since the sustained swimming speed of many fish lies around $0.5 \mathrm{~m} \mathrm{~s}^{-1}$ (Ebel, 2016), angled bar racks with $s=15 \mathrm{~mm}$ can be more suitable for HPPs with low approach flow velocities $U_{o}$ to avoid the risk of fish entrainment while CBRs with $s=50 \mathrm{~mm}$ are suitable for a wide range of approach flow velocities. Flow fields downstream of louvres and MBRs were studied by Kriewitz (2015) and Moretti (2015). These studies were conducted for a similar parameter range as the present research and are hence comparable. Acceptable turbine admission flow conditions were only met for the MBR configuration with $\alpha=15^{\circ}$ and $\beta=45^{\circ}$, but not for the other racks with $\alpha=30^{\circ}$ or $\beta=90^{\circ}$, indicating that the curved bars lead to a more sustainable hydropower production.

The knowledge on the behaviour of migrating fish when encountering a migration barrier is still incomplete. It was observed that fish reacted sensitively to high velocity gradients and shied away from sudden velocity changes (Enders et al., 2012). This observation was confirmed by life-fish experiments comparing louvres with MBRs (Kriewitz, 2015; Boes \& Albayrak, 2017). MBRs leading to milder velocity gradients along the rack as compared to louvres resulted in significantly higher FGEs. Enders et al. (2012) found that salmon smolts started showing avoidance reactions for spatial velocity gradients $\Delta U_{r} / \Delta x \approx 1.0 \div 1.2 \mathrm{~s}^{-1}$ and proposed that this threshold is associated with the energetically optimum swimming speed of fish, which corresponds to about 1 body length $\mathrm{s}^{-1}$. Similar threshold values for salmonids were found by Haro et al. (1998) and Goodwin, Nestler, Anderson, Weber, \& Loucks, (2006). No definite 
threshold values are reported for potamodromous fish species, however. These findings indicate that CBRs leading to spatial velocity gradients along the rack lower than $1.0 \mathrm{~s}^{-1}$ therefore have the potential to guide even fish with weaker swimming capacities.

\subsection{Engineering application}

The flow field at FGSs is affected by several parameters. The bar angle $\beta$ has the most significant impact on the flow field up- and downstream of the CBRs. CBRs with $\beta=45^{\circ}$ clearly show the flow straightening effect of curved bars resulting in a quasi-symmetrical admission flow distribution downstream of the rack. According to Boes \& Albayrak (2017), the FGEs for five European fish species in etho-hydraulic laboratory tests are significantly higher for MBRs with $\beta=45^{\circ}$ than for $\beta=90^{\circ}$. Since upstream velocity gradients are decreased, admission flow distribution is improved, head losses are significantly lower, and the FGEs of CBRs are assumed to be similar to those of MBRs, the authors recommend CBRs with $\beta=45^{\circ}$ (tests $\mathrm{A} 1, \mathrm{~A} 3$ and A5) over those with $\beta=90^{\circ}$ (tests A2, A4 and A6).

For $\beta=45^{\circ}$ the rack angle $\alpha$ has a minor effect on the flow fields, i.e. $U_{\max }$, spatial velocity gradients and admission flow distribution. For $\beta=90^{\circ}$, however, flow conditions improve for $\alpha$ $=15^{\circ}$ as compared to $\alpha=30^{\circ}$ or $45^{\circ}$. Furthermore, $v_{p} / v_{n}$ values are more favourable for fish guidance with decreasing $\alpha$. The life-fish test results reported by Boes $\&$ Albayrak (2017) reveal similar FGEs for MBRs with $\alpha=15^{\circ}$ or $30^{\circ}$ with a bottom overlay for five tested fish species. EPRI \& DML (2001) showed high FGE for milder rack angles, i.e. $\alpha=15^{\circ}$ for the tested North American fish species. Therefore, we expect similar or even higher FGEs for CBR than for louvres and MBRs because of the improved flow fields. The criterion $v_{p} / v_{n}>1$ proposed by Courret \& Larinier (2008) is fulfilled for all tested CBR configurations. For CBRs with a clear bar spacing $s=50 \mathrm{~mm}$, the criterion $v_{n}>0.5 \mathrm{~m} \mathrm{~s}^{-1}$ (Ebel, 2016) might be particularly critical for small fish due to their reduced sustained swimming speed. Small fish might get entrained between the bars if $v_{n}$ values are high. For CBRs, the $v_{n} / U_{o}$ values decrease with decreasing $\alpha$. Consequently, a smaller rack angle might be suitable for HPPs with higher approach flow velocities $U_{o}$ in order to decrease $v_{n}$. The authors therefore recommend CBRs with $\alpha=15^{\circ} \div 30^{\circ}$ (A3 and A5) and to select $\alpha$ by consulting Fig. 3a considering site-specific parameters, i.e. $U_{o}$ or geometric restrictions.

Top and bottom overlays not only provide a physical barrier for fish, they also increase the guidance effect for fish migrating close to the water surface or the channel bed (Odeh \& Orvis, 1998; Amaral et al., 2003; EPRI \& DML, 2001; Boes \& Albayrak, 2017). A top overlay further guides large drift wood along the rack preventing wood accumulations at the rack (Gudde, 2016), while a bottom overlay may promote the guidance of sediments to the bypass. Between the overlays, however, $v_{p} / v_{n}$ values are decreased, which locally reduces the guidance effect. 
Additional overlay blockage slightly deteriorates the turbine admission flow distribution but only marginally increases the head loss (Table 2). The $v_{p}$ values increase while $v_{n}$ values decrease in front of the overlays reducing the risk of fish entrainment through the CBR. Ebel (2016) recommends minimum absolute values of $h_{B o} \geq 0.5 \mathrm{~m}$ and $h_{T o} \geq 1.0 \mathrm{~m}$. Based on our findings, however, we recommend the application of both top and bottom overlay not exceeding $h_{v}=0.20$ $\div 0.30 \cdot h_{o}$ (B2 or B5) for high FGE and mitigation of operational issues by considering geometrical and operational site-specific conditions.

Overall, the present results imply that the use of the recommended CBR configurations as fish guidance structures (A3, A5, B2 or B5) at HPPs neither negatively affect turbine admission flow nor hydropower production. With the demonstrated hydraulic performance, CBRs can also be an alternative to horizontal bar racks commonly used at small HPPs (Ebel, 2016) with an advantage of mitigating common clogging problems of those racks.

\section{Conclusions}

The hydraulics of selected curved-bar rack configurations were systematically investigated at 1:2 Froude-scaled detail models in a laboratory flume. Maximum velocities and velocity gradients upstream of the rack, normal, parallel and vertical velocity components along the rack, and downstream flow distributions were assessed and discussed with regard to fish-biological and turbine admission flow criteria. The key findings of the present research are:

1. Maximum velocities and velocity gradients at the foot of curved-bar racks are significantly lower as compared to the equivalent rack configurations with rectangular bars leading to a more uniform flow distribution along the rack thereby expecting an increased fish guidance.

2. The curved bar shapes promote a flow straightening effect resulting in a quasisymmetric downstream flow field and favourable turbine admission flow.

3. The application of top and/or bottom overlays only slightly deteriorates the turbine admission flow but potentially improves fish guidance as well as diversion of drift wood and sediment transport, respectively.

4. The recommended CBR configuration has a rack angle of $\alpha=15^{\circ} \div 30^{\circ}$, a bar angle of $\beta=45^{\circ}$, a clear bar spacing of $50 \mathrm{~mm}$ and both bottom and top overlays.

Given the highly reduced head loss and the improved up- and downstream hydraulic conditions, curved-bar racks present a promising potential for fish protection and guidance at hydropower plants and water intakes, minimizing economic and operational impacts. 


\section{Acknowledgements}

This project has received funding from the European Union's Horizon 2020 research and innovation programme under grant agreement No. 727830, FITHydro (Fishfriendly Innovative Technologies for Hydropower). The authors would further like to thank the State Secretariat for Education, Research and Innovation (SERI) for their support. VAW's activities in hydropower research are embedded in the Swiss Competence Centre for Energy Research, Supply of Electricity (SCCER-SoE), which is an initiative funded by the Swiss Confederation through Innosuisse (Swiss Innovation Agency).

\section{Abbreviations}

FGE fish guidance efficiency

FGS fish guidance structure

HPP hydropower plant

MBR modified bar rack

CBR curved-bar rack

\section{Notation}

$d=$ bar depth $(\mathrm{m})$

$\mathrm{F}=U_{o} /\left(g \cdot h_{o}\right)^{0.5}=$ Froude number $(-)$

$h_{B o}=$ bottom overlay height $(\mathrm{m})$

$h_{o}=$ approach flow depth $(\mathrm{m})$

$h_{T o}=$ top overlay height $(\mathrm{m})$

$h_{v}=$ total overlay height as a combination of top and bottom overlays $h_{T o}+h_{B o}(\mathrm{~m})$

$l_{R}=$ rack length $(\mathrm{m})$

$Q=\operatorname{discharge}\left(\mathrm{m}^{3} \mathrm{~s}^{-1}\right)$

$\mathrm{R}=4 \cdot R_{h} \cdot U_{o} / v=$ Reynolds number (-)

$\mathrm{R}_{b}=t \cdot U_{o} / v=$ bar Reynolds number

$R_{h}=h \cdot w_{c h} /\left(2 h+w_{c h}\right)=$ hydraulic radius $(\mathrm{m})$

$s=$ clear spacing between bars $(\mathrm{m})$

$t=$ bar thickness (m)

$u, v, w=$ streamwise, spanwise, vertical local, instantaneous velocity component $\left(\mathrm{m} \mathrm{s}^{-1}\right)$

$U, V, W=$ streamwise, spanwise, vertical local, time-averaged velocity component $\left(\mathrm{m} \mathrm{s}^{-1}\right)$

$U_{o}=$ mean approach flow velocity $\left(\mathrm{m} \mathrm{s}^{-1}\right)$

$U_{\max }=$ maximum upstream velocity at the rack foot $\left(\mathrm{m} \mathrm{s}^{-1}\right)$

$U_{r}=$ resulting flow velocity $\left(\mathrm{m} \mathrm{s}^{-1}\right)$

$v_{n}=$ velocity component normal to the rack $\left(\mathrm{m} \mathrm{s}^{-1}\right)$ 
$v_{p}=$ velocity component parallel to the rack $\left(\mathrm{m} \mathrm{s}^{-1}\right)$

$v_{z}=$ vertical velocity component in the rack cross section $\left(\mathrm{m} \mathrm{s}^{-1}\right)$

$w_{c h}=$ flume width $(\mathrm{m})$

$x, y, z=$ streamwise, spanwise and vertical directions $(\mathrm{m})$

$x^{\prime}, y^{\prime}=$ streamwise and spanwise directions in the rack cross section (m)

$\alpha=$ rack angle to flow direction or from wall $\left(^{\circ}\right)$

$\beta=$ bar angle to flow direction $\left(^{\circ}\right)$

$\delta=$ bar angle to downstream or power channel $\left(^{\circ}\right)$

$\Delta h_{R}=$ rack head loss $(\mathrm{m})$

$\left(\Delta U_{r} / \Delta x\right)_{\max }=$ maximum spatial velocity gradient $\left(\mathrm{s}^{-1}\right)$

$\xi_{R}=$ rack head loss coefficient (-)

$\sigma==t /(t+s)=$ non-dimensional axial distance between bars $(-)$

\section{References}

Albayrak, I., Kriewitz, C. R., Beck, C., \& Boes, R. M. (2015). Flow fields around fish guidance structures. E-proceedings of the 36th IAHR World Congress, The Hague, the Netherlands.

Albayrak, I., Kriewitz, C. R., Hager, W. H., \& Boes, R. M. (2017). An experimental investigation on louvres and angled bar racks. Journal of Hydraulic Research, 1-17.

Amaral, S. V. (2003). The use of angled bar racks and louvers for guiding fish at FERCLicensed Projects. FERC Fish Passage Workshop, Holden, USA.

Amaral, S. V., Winchell, F. C., McMahon, B. J., \& Dixon, D. (2003). Evaluation of angled bar racks and louvers for guiding silver phase American eels. Proc. Biology, Management and Protection of Catadromous Eels, 367-376, D.A. Dixon, ed. American Fisheries Society, Bethesda MD.

Bates, D. W., \& Vinsonhaler, R. (1957). Use of louvers for guiding fish. Transactions of the American Fisheries Society, 86(1), 38-57.

Beck, C., Albayrak, I., Meister, J., \& Boes, R. M. (2019). Hydraulic performance of fish guidance structures with curved bars - Part 1: Head loss assessment. Journal of Hydraulic Research

Boes R., \& Albayrak, I. (2017). Fish guidance structures: New head loss formula and fish guidance efficiencies. Proceedings of the $37^{\text {th }}$ IAHR World Congress. Kuala Lumpur, Malaysia.

Boes, R., Albayrak, I., Kriewitz, C. R., \& Peter, A. (2016). Fischschutz und Fischabstieg mittels vertikaler Leitrechen-Bypass-Systeme: Rechenverluste und Leiteffizienz [Fish protection and downstream fish migration by means of guidance systems with vertical bars: head loss and bypass efficiency]. Wasserwirtschaft, 7(8), 29-35 (in German). 
Chatellier, L., Wang, R.-W., David, L., Courret, D., \& Larinier, M. (2011). Experimental characterization of the flow across fish-friendly angled trashrack models. Proceedings of the 34th World Congress of the International Association for Hydro-Environment Research and Engineering: 33rd Hydrology and Water Resources Symposium and 10th Conference on Hydraulics in Water Engineering. Brisbane, Australia.

Courret, D., \& Larinier, M. (2008). Guide pour la conception de prises d'eau "ichtyocompatibles" pour les petites centrales hydroélectriques [Guide for the design of fishfriendly intakes for small hydropower plants]. France : Agence de L'Environnement et de la Maîtrise de l'Energie (ADEME). Retrieved from http://www.onema.fr/IMG/pdf/2008_027.pdf(in French).

Ducharme, L. J. A. (1972). Application of louver deflectors for guiding Atlantic salmon. Journal of the Fisheries Research Board of Canada, 29(10), 1397-1404.

Ebel, G. (2016). Fischschutz und Fischabstieg an Wasserkraftanlagen - Handbuch Rechen- und Bypasssysteme. Ingenieurbiologische Grundlagen, Modellierung und Prognose, Bemessung und Gestaltung Gestaltung [Fish Protection and downstream fish migration at hydropower plants - Handbook for fish guidance and bypass systems]. $2^{\text {nd }}$ edn., Mitteilungen aus dem Büro für Gewässerökologie und Fischereibiologie, Band 4, (in German).

Enders, E. C., Gessel, M. H., Anderson, J. J., \& Williams, J. G. (2012). Effects of decelerating and accelerating flows on juvenile salmonid behavior. Transactions of the American Fisheries Society, 141(2), 357-364.

EPRI (Electric Power Research Institute) \& DML (Dominion Millstone Laboratories) (2001). Evaluation of angled bar racks and louvers for guiding fish at water intakes. Report 1005193: 106. Palo Alto, CA and Waterford, CT.

Godde, D. (1994). Experimentelle Untersuchung zur Anströmung von Rohrturbinen: Ein Beitrag zur Optimierung des Turbineneinlaufs [Experimental investigation of bulb turbine admission flow: Contribution to the intake optimization]. Report Nr. 75. Obernach Research Institute, and Chair of Hydraulic and Water Resources Engineering TU Munich, Germany [in German].

Goring, D. G., Nikora, V. I. (2002). Despiking Acoustic Doppler Velocimeter Data. Journal of Hydraulic Engineering, 128(1), 117-126.

Gudde, A. (2016). Experimentelle Untersuchungen zu Schwemmholz an Fischleitrechen. [Experimental investigation of large wood accumulations at fish guidance structures]. Master Thesis, Laboratory of Hydraulics, Hydrology and Glaciology (VAW), ETH Zurich, Zürich, Switzerland (in German). 
Goodwin, R. A., Nestler, J. M., Anderson, J. J., Weber, L. J., \& Loucks, D. P. (2006).

Forecasting 3-D fish movement behavior using a Eulerian-Lagrangian-agent method (ELAM). Ecological Modelling, 192: 197-223.

Haro, A., Odeh, M., Noreike, J., \& Castro-Santos, T. (1998). Effect of water acceleration on downstream migratory behavior and passage of Antlantic salmon smolts and juvenile American shad at surface bypasses. Transactions of the American Fisheries Society, 127: 118-127.

Katopodis, C., Ead, S.A., Standen, G., Rajaratnam, N. (2005). Structure of flow upstream of vertical angled screens in open channels. Journal of Hydraulic Engineering, 131(4), 294304

Kriewitz, C. R. (2015). Leitrechen an Fischabstiegsanlagen - Hydraulik und fischbiologische Effizienz [Guidance screens at fish protection facilities - Hydraulics and fish-biological efficiency]. VAW-Mitteilung 230, R. M. Boes, ed. Laboratory of Hydraulics, Hydrology and Glaciology (VAW), ETH Zurich, Zürich, Switzerland (in German).

Lane, S. M., Biron, K. F., Bradbrook, K. F., Butler, J. B., Chandler, J. H., Crowell, M. D., McLelland, S. J., Richards, K. S., \& Roy, A.G. (1998). Three-dimensional measurement of river channel flow processes using acoustic Doppler velocimetry. Earth Surface Processes and Landforms, 23, 1247-1267

Moretti, G. (2015). Strömungsstrukturen um fischleitende Strukturen [Flow fields around fish guidance structures]. Master Thesis, Laboratory of Hydraulics, Hydrology and Glaciology (VAW), ETH Zurich, Zürich, Switzerland (in German).

Nestler, J. M., Goodwin, R. A., Smith, D. L., Anderson, J. J., \& Li, S. (2008). Optimum fish passage and guidance desings are based in the hydrogeomorphology of natural rivers. River Research and Applications, 24: 148-168.

Odeh, M. \& Orvis, C. (1998). Downstream fish passage design considerations and developments at hydroelectric projects in the northeast USA. Proc. Fish Migration and Fish Bypasses, Fishing News Books: 267-280.

Raynal, S., Chatellier, L., Courret, D., Larinier, M., \& David L. (2013). An experimental study on fish-friendly trashracks - Part 2. Angled trashracks. Journal of Hydraulic Research, 51(1), 67-75.

Shepherd, D., Katopodis, C., \& Rajaratnam, N. (2007). An experimental study of louvers for fish diversion. Canadian Journal of Civil Engineering, 34(6), 770-776.

Silva, A.T.; Katopodis, C.; Tachie, M.F.; Santos, J.M.; Ferreira, M.T. (2016). Downstream swimming behaviour of catadromous and potamodromous fish over spillways. River Research and Applications, 32: 935-945. 
USBR (United States Bureau of Reclamation) (2006). Fish protection at water diversions: a guide for planning and designing fish exclusion facilities. US Department of the Interior, Bureau of Reclamation.

USBR (United States Bureau of Reclamation) (2011). Modifications to bypass system operations to improve hydraulics at the tracy fish collection facility. Volume 47, US Department of the Interior, Bureau of Reclamation. 


\section{List of tables}

Table 1: Test matrix with geometric parameters of CBR configurations without overlay (Tests A1-A6) and with top, top \& bottom, or bottom overlay (Tests B1-B6), as well as horizontal measuring planes relative to the flow depth

Table 2 Hydraulic parameters and turbine admission flow distribution measured at $x / h_{o}=3.5$; the criteria proposed by Godde (1994) are fully met (+), almost met (o) or not met (-); rack head loss coefficients $\xi_{R}$ from Beck et al., (2019) 


\section{List of figures}

Figure 1 Geometric and hydraulic rack parameters (a) flume top view with the flume $(x, y)$ and rack ( $x^{\prime}, y^{\prime}$ along the grey line ) coordinate systems; (b) top view of cross-sectional bar shapes with prototype dimensions; and (c) side view of the CBR with overlays

Figure 2 Flow field of CBR configuration (a), (b) A3: $\alpha=30^{\circ}, \beta=45^{\circ}, \sigma=0.17$ and (c), (d) A4: $\alpha=30^{\circ}, \beta=90^{\circ}, \sigma=0.17$ measured at $z / h_{o}=0.5$; the direction of the resulting velocity vector at each measurement point and the contour values are indicated for (a), (c) longitudinal flow velocities $U / U_{o}$ and (b), (d) transversal flow velocities $V / U_{o}$

Figure 3 Comparison of velocity components (a) normal to the rack $\left(v_{n}\right)$ normalized with approach flow velocity $U_{o},(\mathrm{~b})$ vertical $\left(v_{z}\right)$ and parallel $\left(v_{p}\right)$ to the rack normalized with $U_{o}$ and (c) the ratio $v_{p} / v_{n}$ for the tests A1-A6 measured at $z / h_{o}=0.5$, the dashed line (---) showing the threshold values as a criterion for fish guidance efficiency

Figure 4 Flow field of CBR configuration with $\alpha=30^{\circ}, \beta=45^{\circ}, \sigma=0.17$ (a), (b) without overlay (A3) and (c), (d) with bottom overlay $h_{B o}=0.15 h_{o}$ (B6), measured at $z / h_{o}=0.075$. The resulting velocity vector at each measurement point and the contour values are indicated for (a), (c) longitudinal flow velocities $U / U_{o}$ and (b), (d) transversal flow velocities $V / U_{o}$

Figure 5 Contour plots of flow velocities along the rack (view in flow direction), (a) A3: no overlay (b) B4: 15\% top overlay, (c) B6: 15\% bottom overlay and (d) B5: 15\% top and 15\% bottom overlay; the overlay dimensions are indicated; the positions $y^{\prime} / l_{R}=0.0$ and 1.0 mark the rack head and the rack foot, respectively

Figure 6 Contour plots of flow velocities in the downstream cross section $x / h_{o}=3.5$. (a) A4: $\alpha=$ $30^{\circ}, \beta=90^{\circ}$, (b) A3: $\alpha=30^{\circ}, \beta=45^{\circ}$ and (c) B5: A3 with $h_{v}=0.3 h_{o}$. The velocity criterion is listed in each quadrant, whereas the discharge criterion is given above each plot; the water level and the measuring grid are indicated; view in flow direction 
Table 1: Test matrix with geometric parameters of CBR configurations without overlay (Tests A1-A6) and with top, top \& bottom, or bottom overlay (Tests B1-B6), as well as horizontal measuring planes relative to the flow depth

\begin{tabular}{|c|c|c|c|c|c|}
\hline Test & $\alpha$ & $\beta$ & $\sigma$ & $h_{v}$ & $z / h_{o}$ \\
\hline A1 & \multirow{2}{*}{$45^{\circ}$} & $45^{\circ}$ & \multirow{6}{*}{0.17} & \multirow{6}{*}{ - } & $0.25,0.50,0.75$ \\
\hline A2 & & $90^{\circ}$ & & & $0.25,0.50,0.75$ \\
\hline A3 & \multirow{2}{*}{$30^{\circ}$} & $45^{\circ}$ & & & $0.075,0.25,0.50,0.75,0.85$ \\
\hline A4 & & $90^{\circ}$ & & & $0.25,0.50,0.75$ \\
\hline A5 & \multirow{2}{*}{$15^{\circ}$} & $45^{\circ}$ & & & $0.25,0.50,0.75$ \\
\hline A6 & & $90^{\circ}$ & & & $0.25,0.50,0.75$ \\
\hline B1 & \multirow{6}{*}{$30^{\circ}$} & \multirow{6}{*}{$45^{\circ}$} & \multirow{6}{*}{0.17} & $h_{T o}=0.10 h_{o}$ & \multirow{6}{*}{$0.075,0.85$} \\
\hline B2 & & & & $\begin{array}{l}h_{T o}=0.10 h_{o} \\
h_{B o}=0.10 h_{o}\end{array}$ & \\
\hline B3 & & & & $h_{B o}=0.10 h_{o}$ & \\
\hline B4 & & & & $h_{T o}=0.15 h_{o}$ & \\
\hline B5 & & & & $\begin{array}{l}h_{T o}=0.15 h_{o} \\
h_{B o}=0.15 h_{o}\end{array}$ & \\
\hline B6 & & & & $h_{B o}=0.15 h_{o}$ & \\
\hline
\end{tabular}


Table 2 Hydraulic parameters and turbine admission flow distribution measured at $x / h_{o}=3.5$; the criteria proposed by Godde (1994) are fully met (+), almost met (o) or not met (-); rack head loss coefficients $\xi_{R}$ from Beck et al., (2019)

\begin{tabular}{|c|c|c|c|c|c|c|c|}
\hline Test & $\xi_{R}$ & $h_{v}$ & $U_{\max } / U_{o}$ & $\begin{array}{c}\text { Discharge per } \\
\text { intake half }(\%)\end{array}$ & $\begin{array}{c}\text { Velocity per intake } \\
\text { quadrant (\%) }\end{array}$ & \\
\hline A1 & 0.70 & 0 & 1.25 & $47.9 / 52.1$ & + & $-4.2 / 4.0 /-4.2 / 4.4$ & + \\
\hline A2 & 4.05 & 0 & 1.66 & $35.6 / 64.4$ & - & $-29.6 / 26.8 /-28.0 / 30.8$ & - \\
\hline A3 & 0.57 & 0 & 1.27 & $48.7 / 51.3$ & + & $-2.6 / 2.0 /-3.4 / 3.9$ & + \\
\hline A4 & 3.83 & 0 & 1.87 & $33.9 / 66.1$ & - & $-29.3 / 32.4 /-34.2 / 31.1$ & - \\
\hline A5 & 0.80 & 0 & 1.36 & $49.5 / 50.5$ & + & $-4.0 / 2.3 /-3.0 / 4.7$ & + \\
\hline A6 & 2.19 & 0 & 1.56 & $45.1 / 54.9$ & $\mathrm{o}$ & $-12.2 / 9.7 /-7.5 / 10.0$ & $\mathrm{o}$ \\
\hline $\mathrm{B} 1$ & 0.55 & $h_{T o}=0.10 h_{o}$ & $\mathrm{n} / \mathrm{a}$ & $48.2 / 51.8$ & + & $6.1 / 5.4 /-13.9 / 2.4$ & $\mathrm{o}$ \\
\hline B2 & 0.58 & $\begin{array}{l}h_{T o}=0.10 h_{o} \\
h_{B o}=0.10 h_{o}\end{array}$ & $\mathrm{n} / \mathrm{a}$ & $46.4 / 53.6$ & $\mathrm{o}$ & $-0.2 / 7.4 /-13.0 / 5.9$ & $\mathrm{o}$ \\
\hline B3 & 0.67 & $h_{B o}=0.10 h_{o}$ & $\mathrm{n} / \mathrm{a}$ & $49.7 / 50.3$ & + & $-7.7 / 1.2 / 3.2 / 3.3$ & + \\
\hline B4 & 0.60 & $h_{T o}=0.15 h_{o}$ & 1.13 & $49.2 / 50.8$ & + & $6.4 / 5.5 /-12.5 / 0.5$ & $\mathrm{o}$ \\
\hline B5 & 0.76 & $\begin{array}{l}h_{T o}=0.15 h_{o} \\
h_{B o}=0.15 h_{o}\end{array}$ & 1.13 & $44.7 / 55.3$ & - & $-1.0 / 12.9 /-20.9 / 9.0$ & - \\
\hline B6 & 0.64 & $h_{B o}=0.15 h_{o}$ & 1.17 & $49.5 / 50.5$ & + & $-8.1 /-0.4 / 5.1 / 3.4$ & + \\
\hline
\end{tabular}


(a)

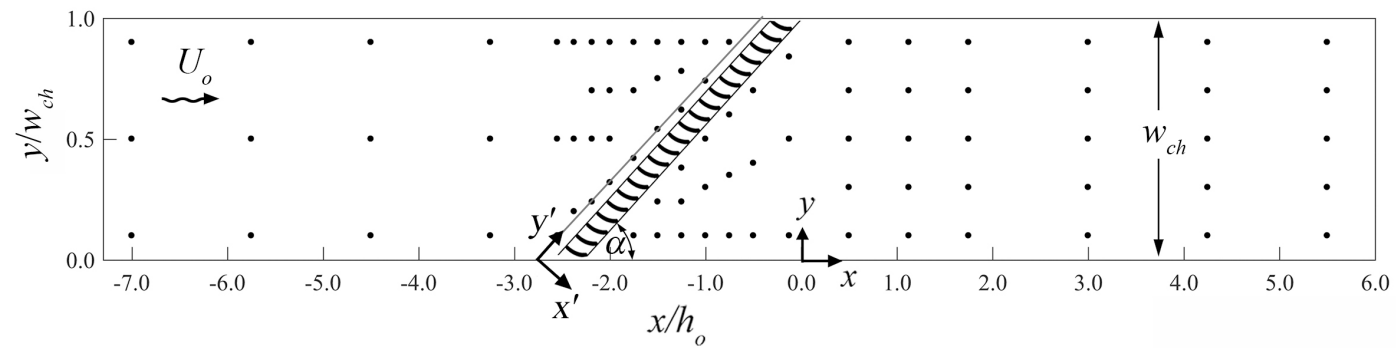

(b)

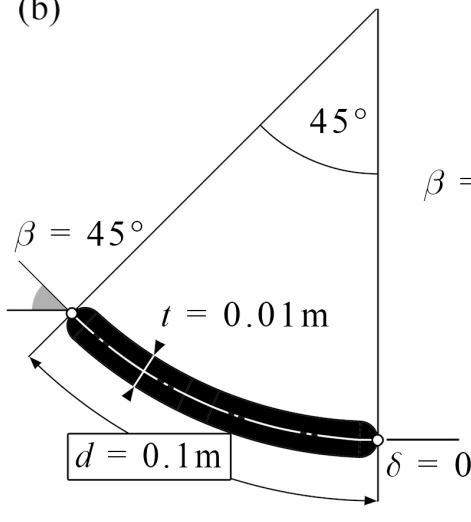

(c)

Figure 1 Geometric and hydraulic rack parameters (a) flume top view with the flume $(x, y)$ and rack ( $x^{\prime}, y^{\prime}$ along the grey line ) coordinate systems; (b) top view of cross-sectional bar shapes with prototype dimensions; and (c) side view of the CBR with overlays 
(a)

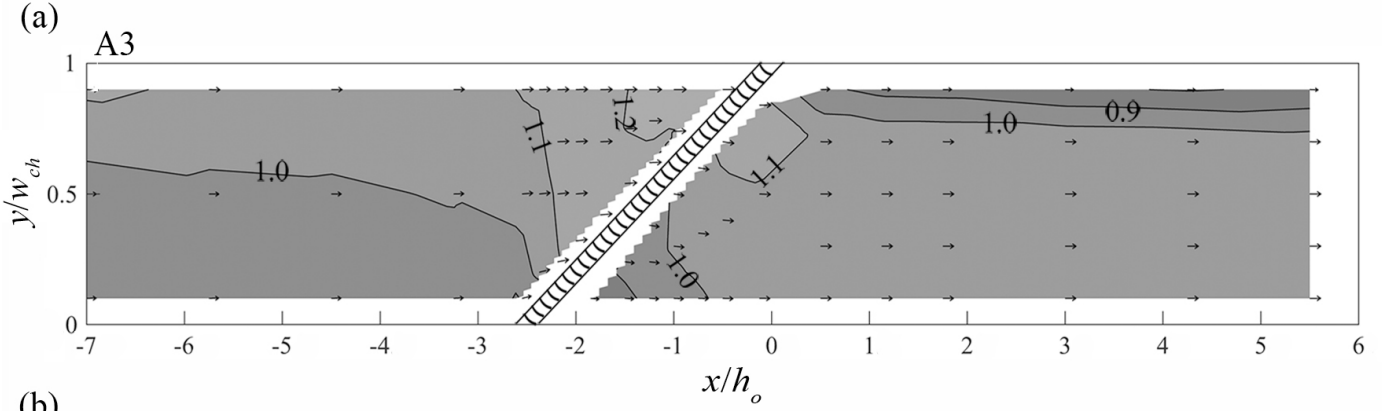

$U / U_{\text {o }}$
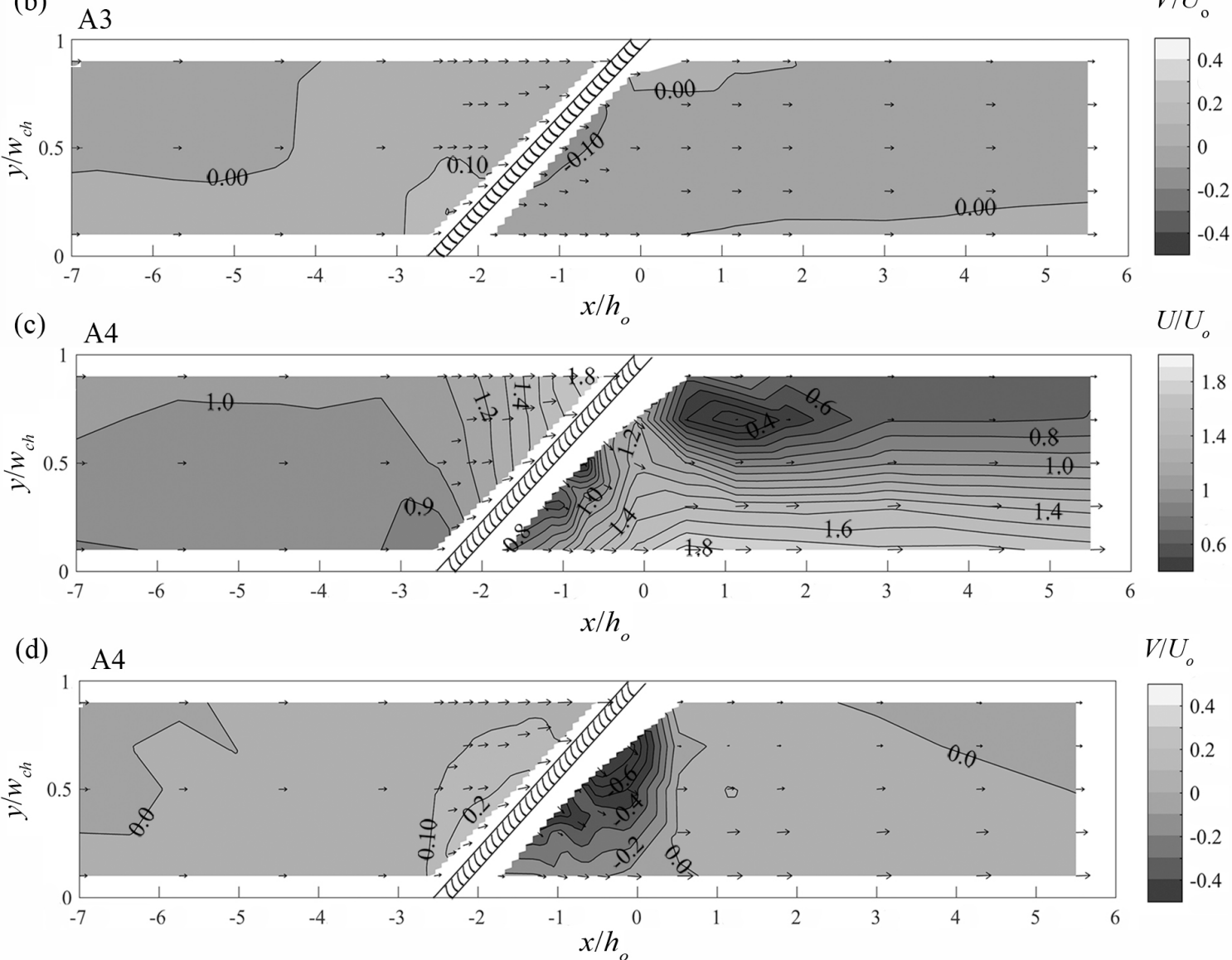

Figure 2 Flow field of CBR configuration (a), (b) A3: $\alpha=30^{\circ}, \beta=45^{\circ}, \sigma=0.17$ and (c), (d) A4: $\alpha=30^{\circ}, \beta=90^{\circ}, \sigma=0.17$ measured at $z / h_{o}=0.5$; the direction of the resulting velocity vector at each measurement point and the contour values are indicated for (a), (c) longitudinal flow velocities $U / U_{o}$ and (b), (d) transversal flow velocities $V / U_{o}$ 
(a)

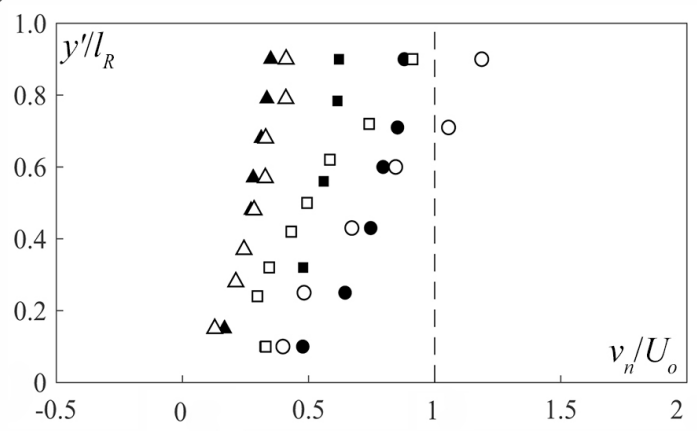

- $\mathrm{A} 1: \alpha=45^{\circ}, \beta=45^{\circ}$

- $\mathrm{A} 3: \alpha=30^{\circ}, \beta=45^{\circ}$

(A $\mathrm{A} 5: \alpha=15^{\circ}, \beta=45^{\circ}$

$\mathrm{OA} 2: \alpha=45^{\circ}, \beta=90^{\circ}$

$\mathrm{A} 4: \alpha=30^{\circ}, \beta=90^{\circ}$

$\triangle \mathrm{A} 6: \alpha=15^{\circ}, \beta=90^{\circ}$

(b)

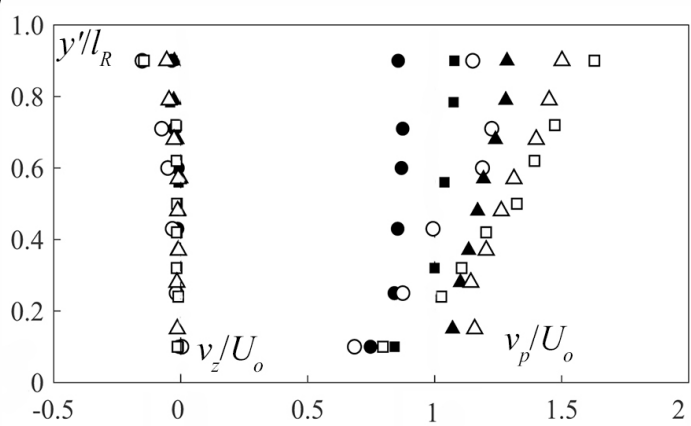

(c)

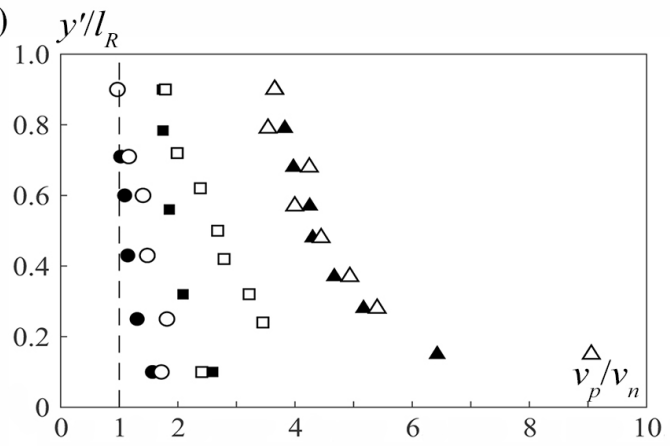

Figure 3 Comparison of velocity components (a) normal to the rack $\left(v_{n}\right)$ normalized with approach flow velocity $U_{o},(\mathrm{~b})$ vertical $\left(v_{z}\right)$ and parallel $\left(v_{p}\right)$ to the rack normalized with $U_{o}$ and (c) the ratio $v_{p} / v_{n}$ for the tests A1-A6 measured at $z / h_{o}=0.5$, the dashed line (---) showing the threshold values as a criterion for fish guidance efficiency 

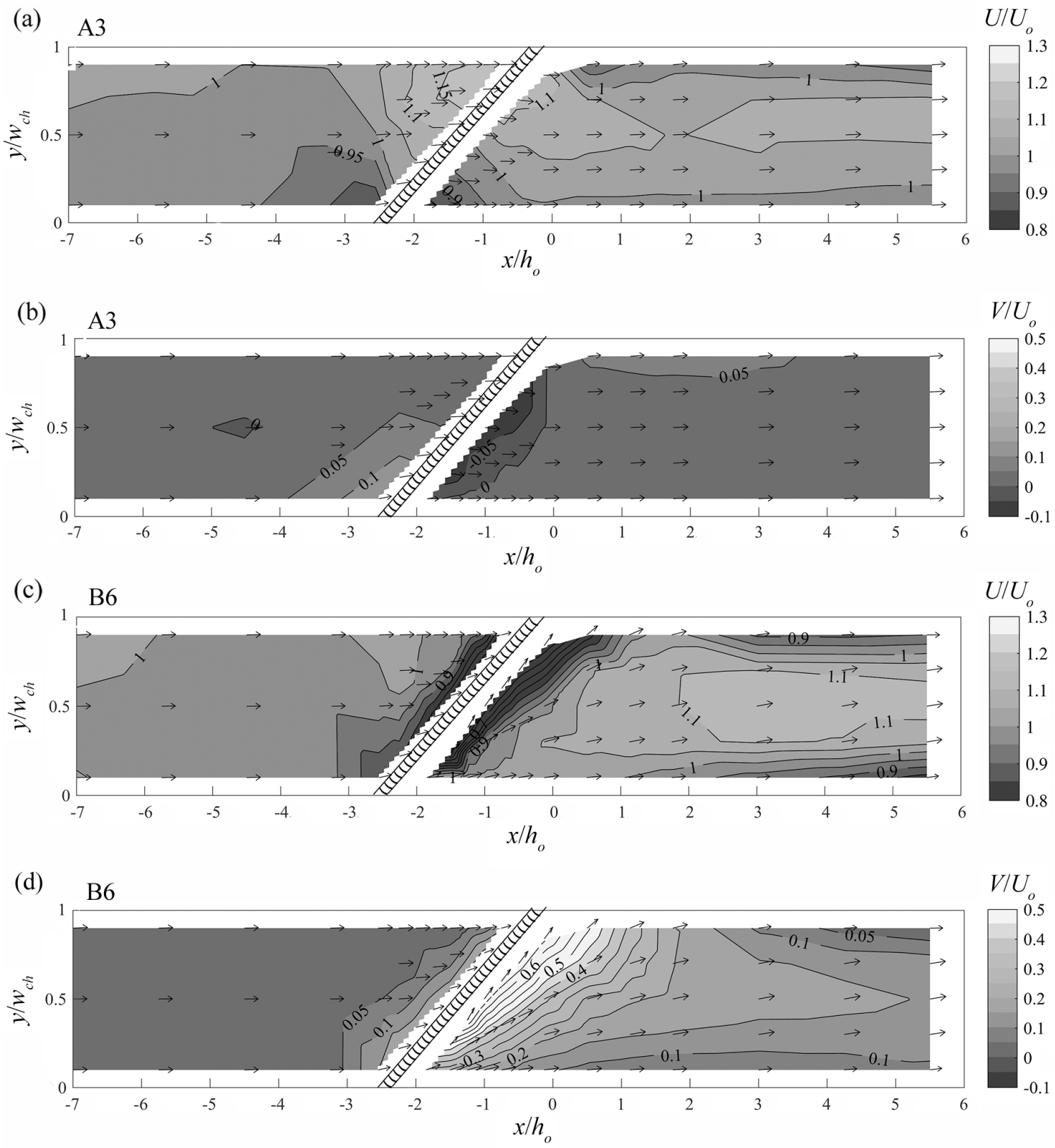

Figure 4 Flow field of CBR configuration with $\alpha=30^{\circ}, \beta=45^{\circ}, \sigma=0.17$ (a), (b) without overlay (A3) and (c), (d) with bottom overlay $h_{B o}=0.15 h_{o}$ (B6), measured at $z / h_{o}=0.075$. The resulting velocity vector at each measurement point and the contour values are indicated for (a), (c) longitudinal flow velocities $U / U_{o}$ and (b), (d) transversal flow velocities $V / U_{o}$ 
(a) $\longleftarrow v_{p, z} / U_{\varphi}=1[-]$

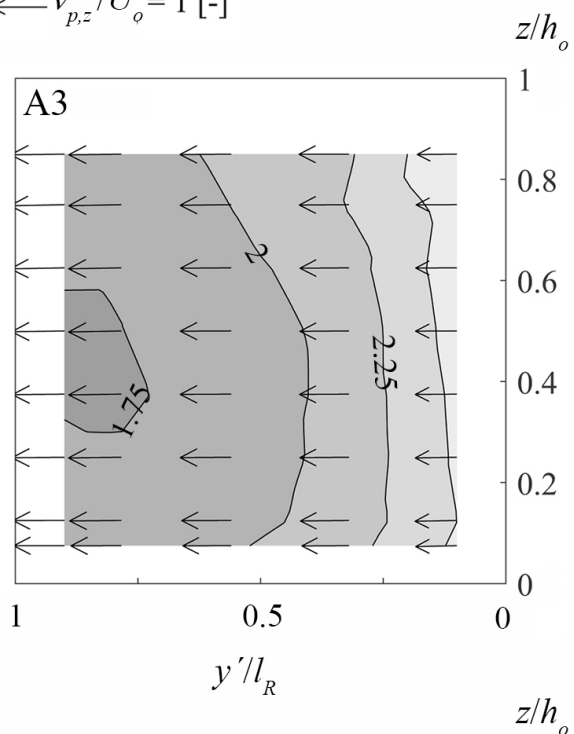

(c)

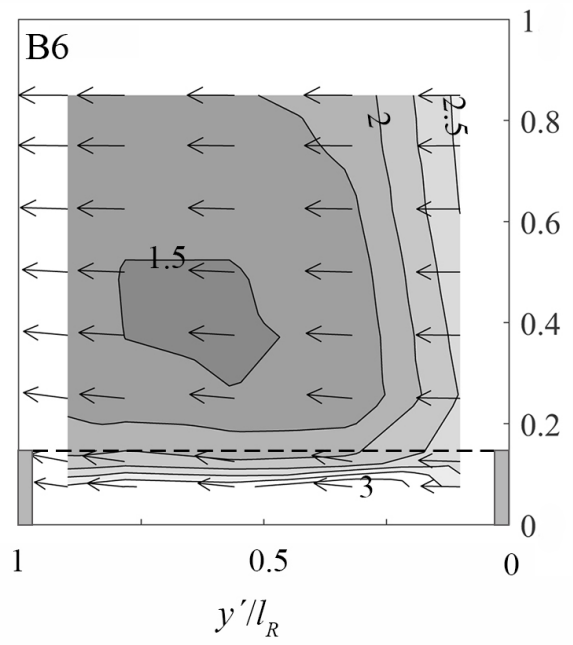

(b)

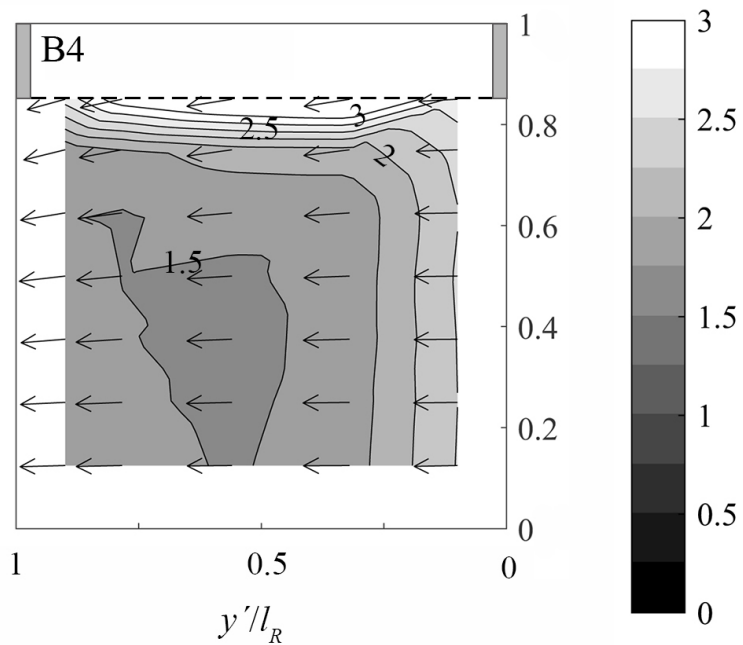

(d)

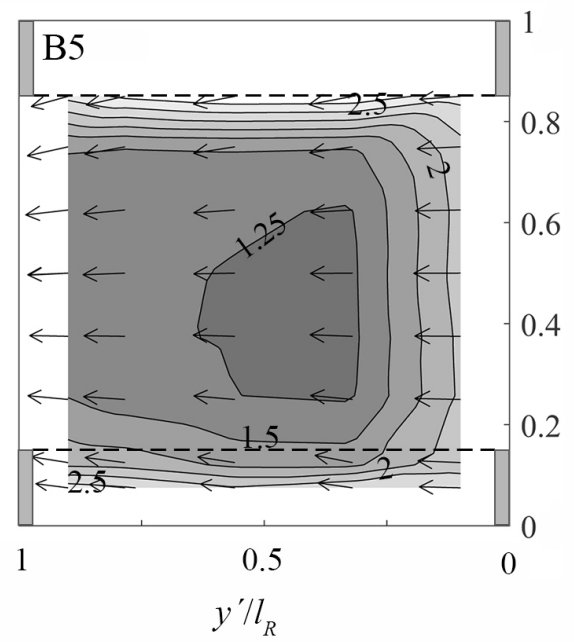

Figure 5 Contour plots of flow velocities along the rack (view in flow direction), (a) A3: no overlay (b) B4: 15\% top overlay, (c) B6: 15\% bottom overlay and (d) B5: 15\% top and 15\% bottom overlay; the overlay dimensions are indicated; the positions $y^{\prime} / l_{R}=0.0$ and 1.0 mark the rack head and the rack foot, respectively 

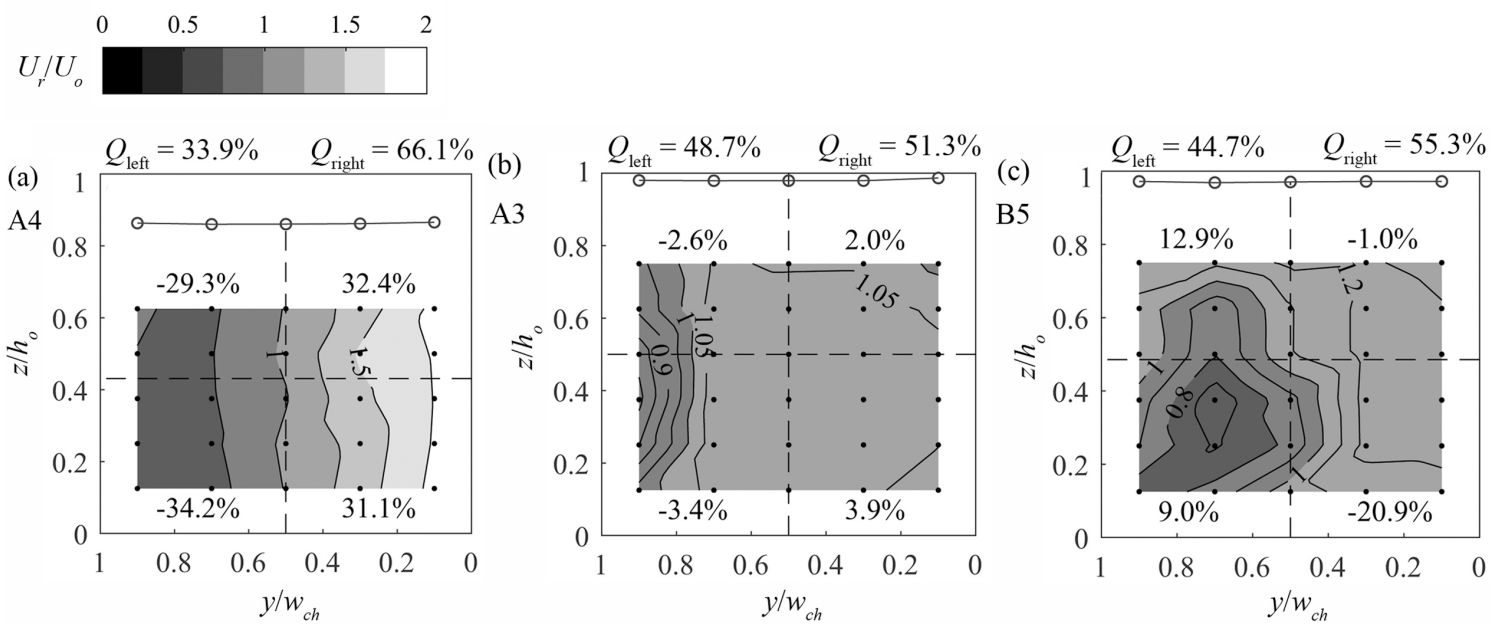

Figure 6 Contour plots of flow velocities in the downstream cross section $x / h_{o}=3.5$. (a) A4: $\alpha=$ $30^{\circ}, \beta=90^{\circ}$, (b) A3: $\alpha=30^{\circ}, \beta=45^{\circ}$ and (c) B5: A3 with $h_{v}=0.3 h_{o}$. The velocity criterion is listed in each quadrant, whereas the discharge criterion is given above each plot; the water level and the measuring grid are indicated; view in flow direction 